Article

\title{
Reconstructed Inter-Annual Variation in September-October Precipitation for the Upper Reaches of the Heihe River and Its Implications for Regional Drought Conditions
}

\author{
Bo Wang ${ }^{1,2}$ (1) , Tuo Chen ${ }^{1, *}$, Guobao $\mathrm{Xu}^{1}$ and Guoju $\mathrm{Wu}^{1}$ \\ 1 State Key Laboratory of Cryospheric Science, Northwest Institute of Eco-Environment and Resources, \\ Chinese Academy of Sciences, Lanzhou 730000, China; wangbo900824@lzb.ac.cn (B.W.); \\ xgb234@1zb.ac.cn (G.X.); guojuwu@163.com (G.W.) \\ 2 University of Chinese Academy of Sciences, Beijing 100049, China \\ * Correspondence: chentuo@lzb.ac.cn; Tel.: +86-093-1496-7373
}

Academic Editor: Ignacio García-González

Received: 2 May 2017; Accepted: 14 July 2017; Published: 29 July 2017

\begin{abstract}
Due to the lack of available long-term climatic records, data related to past autumn precipitation variability throughout Northwest China, especially high-frequency variation, remains limited. In this study, it was found that inter-annual changes in Qinghai spruce radial growth were significantly and negatively $(p<0.05)$ correlated to inter-annual differences in precipitation during the late growing season (September-October) at all sampling sites in the upper reaches of the Heihe River. Based on the growth-climate relationship, a reconstruction of the inter-annual variation in September-October precipitation from 1839 was developed. With the help of this reconstruction, we successfully captured increased inter-annual variations in September-October precipitation during 1855-1861, 1892-1902, and 1969-1986. Furthermore, we found that increased precipitation variation might be related to variation in the westerlies and instability in the relationship between the regional westerly and precipitation. Moreover, our reconstructed data significantly correlated to the drought index (i.e., October SPEI_01) and moisture-related parameters (i.e., September-October cloud fraction), suggesting that our reconstructed data could be used as an indicator of the drought condition in the Heihe River Basin during the late growing season.
\end{abstract}

Keywords: dendroclimatology; inter-annual change; precipitation; late growing-season; drought condition; Heihe River Basin

\section{Introduction}

Climate change, which has resulted in hydrological and water resource changes, has been a hot topic of scientific research [1]. Changes in hydrological processes and water resources have generated increased interest and sometimes concern; water resources have played key roles in the eco-environment, the economy, and social development [2,3]. With a large proportion of the world's population currently experiencing water stress [4], and warming-related droughts inducing increased plant mortality [5], the impact of climate change on water supplies is an understandable concern. Accordingly, increased attention must be paid to changes in precipitation, a major supplier of fresh water resources, particularly in arid and semi-arid regions. This is restricted, however, by available meteorological datasets, which are sparse and limited to less than one century. In northwest China, which includes typical arid and semi-arid regions, we have had only had a limited understanding of past precipitation changes. Therefore, the inclusion of climatic indicators, such as ice cores [6], lake 
sediment [7], loess [8], biologic indicators [9], and tree-rings, are needed as proxies to better understand the long-term variations in precipitation in northwest China [10].

Dendrochronology has been regarded as an important methodology due to its high resolution, accuracy, reliability, and strong consecutiveness [11]. Moreover, tree-ring proxies are readily available and therefore widely used around the world to develop long historical records on climate changes [12]. Several studies have contributed precipitation reconstruction data based on dendrochronological results in Northwest China. For example, Yang et al. [13] established the current longest (from 2637 BC to 2011 AD) annually-resolved and absolutely-dated ring-width chronology for the Northeastern Tibetan Plateau from Qilian juniper (Juniperus przewalskii Kom.) specimens, and developed a 3500-year annual precipitation reconstruction for this region. Zhang et al. [14], Chen et al. [15], and Yang et al. [16] presented long-term annual rainfall histories for the central-Qilian Mountains and the Hexi Corridor in the arid Northwest China, utilizing dendroclimatological methods in their studies. With the help of these precipitation reconstructions, it was suggested that associations exist between precipitation in northwest China and the temperature [13], El Niño-Southern Oscillation circulation (ENSO) [14], westerlies [15], and the Asian summer monsoon [16], and that further warming might contribute to an even greater moisture supply in the Northeastern Tibetan Plateau [13].

However, as suggested by the previous review published by Gallinat et al. [17], autumn remains a relatively neglected season in such climate change research. Knowledge of autumnal precipitation variation is still limited and the related data still sparse [13-16]. Furthermore, occurrences of climatic extremes (i.e., droughts, floods, cloudy rain, and rainstorms) were reported to be frequent in China, with widespread effects [18]. Especially in autumn, which is the season for crop maturity and harvest, it was reported that such climatic extremes struck China more frequently, causing unprecedented water crises and large economic losses [19]. Research on high-frequency changes in climate factors (i.e., inter-annual changes in precipitation), which are closely related to these climate extremes, has remained limited, however. Accordingly, additional reference data is needed to provide more abundant and reliable information on climate changes in autumn, particularly regarding high-frequency variations in precipitation in arid and semi-arid regions of Northwest China, where autumn events signal the end of the growing season for most plant species.

As a widely distributed, easily available, long-lived, humidity-sensitive tree species in the arid and semi-arid mountainous areas, Qinghai spruce (Picea crassifolia Kom.) have been consistently used to develop long-term historical records of climate variations in Northwest China. For example, Liu et al. reconstructed precipitation variations in the Changling-Shoulu region [20] and Xinglong Mountain [20,21]. Tian et al. [22], Deng et al. [23], and Gou et al. [24] reconstructed aridity changes for different parts of the Qilian Mountains, utilizing Qinghai spruce tree-ring width data. Hence, Qinghai spruce, one of the dominant tree species in the study area, was selected for investigation. The objectives of this study were: (1) to reconstruct long-term variations in inter-annual precipitation (IADP) in the late growing season (September-October) for the upper reaches of the Heihe River using tree-ring width data from Qinghai spruce; (2) to explore the implications for drought conditions in the Heihe River Basin; and (3) to determine the potential association between precipitation variations and the westerlies. This study could provide new fundamental information for climate change research and afford new clues for drought prediction in the Heihe River Basin.

\section{Materials and Methods}

\subsection{Study Area and Fieldworks}

The study area was located in the middle Qilian Mountains, in the upper reaches of the Heihe River (Figure 1). Climate data taken from the nearest meteorological station (Qilian station, $100.15^{\circ} \mathrm{E}$, $38.11^{\circ} \mathrm{N}, 2787 \mathrm{~m}$ a.s.l.) showed that the annual average temperature in the study area is $1.08^{\circ} \mathrm{C}$, the total precipitation is $403.60 \mathrm{~mm}$, and the relative humidity is $53.42 \%$. Qinghai spruce grows sparsely on shady and partly-shaded slopes in this area. This coniferous species is tolerant to cold environments 
and poor soils, allowing the species to grow along an extensive elevation range (from $2600 \mathrm{~m}$ to $3200 \mathrm{~m}$ a.s.l.) within the study area. High-elevation Qinghai spruce in this area has been well protected, being situated within fairly inaccessible areas at low densities, resulting in very little disturbance from human activity. We conducted fieldworks at three separate sites in the upper reaches of the Heihe River in July-August 2012 and June 2013 (Figure 1; Table 1). A rectangular sampling plot of Qinghai spruce was established at each site. We collected tree-ring cores at the tree breast height (approximately $1.3 \mathrm{~m}$ above the ground surface) using $5 \mathrm{~mm}$ diameter increment borers. Every tree in the sampling plots was cored. One to two tree-ring cores were extracted from each tree. In total, we sampled 310 trees at sites Dayekou (dyk), Qingyanggou (qyg) and Zhamashi (zms) (Figure 1, Table 1).

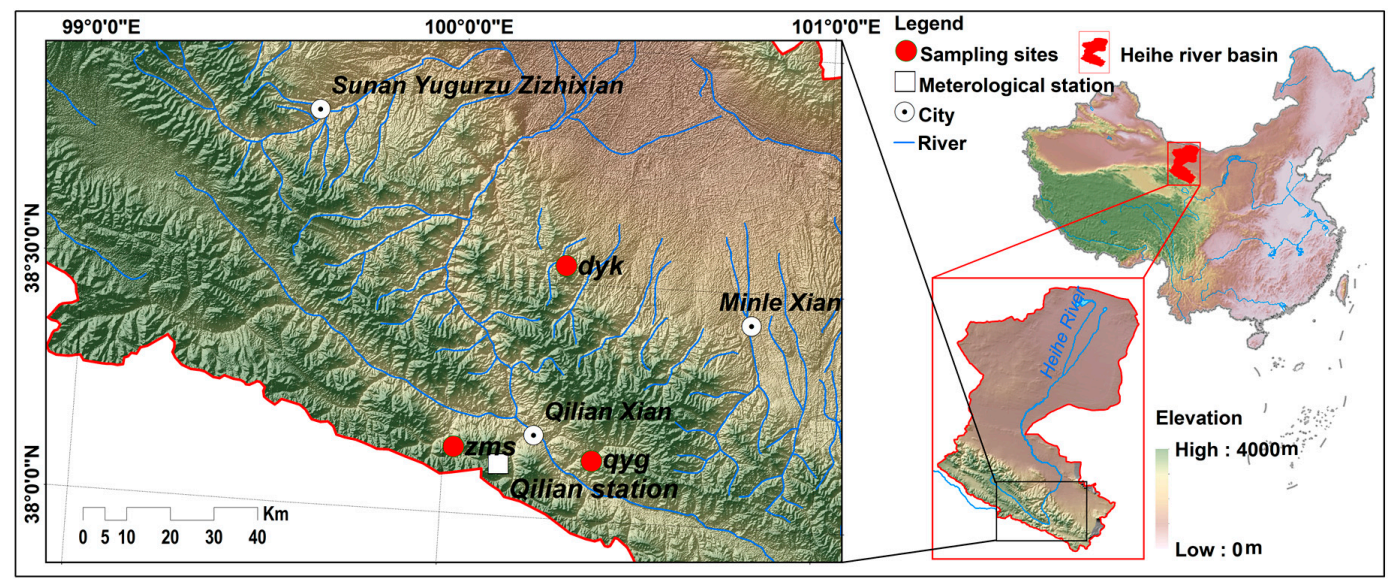

Figure 1. Location map of the study area showing the position and topography of sampling sites and nearest meteorological stations in the upper reaches of the Heihe river.

Table 1. The information of fixed sampling plots at the upper reaches of the Heihe river.

\begin{tabular}{|c|c|c|c|}
\hline Site Code Statistics & dyk & qyg & zms \\
\hline Site Name & Dayekou & Qingyanggou & Zhamashi \\
\hline Longitude & $100^{\circ} 18^{\prime} 06^{\prime \prime} \mathrm{E}$ & $100^{\circ} 23^{\prime} 59^{\prime \prime} \mathrm{E}$ & $100^{\circ} 01^{\prime} 36^{\prime \prime} \mathrm{E}$ \\
\hline Latitude & $38^{\circ} 32^{\prime} 19^{\prime \prime} \mathrm{N}$ & $38^{\circ} 07^{\prime} 39^{\prime \prime} \mathrm{N}$ & $38^{\circ} 08^{\prime} 28^{\prime \prime} \mathrm{N}$ \\
\hline Altitude(m) & 3098 & 3340 & 3310 \\
\hline Slope aspect ${ }^{1}$ & $\mathrm{~N}$ & $\mathrm{NE}$ & $\mathrm{NE}$ \\
\hline Tree density (stems/ha) & 1100 & 1622 & 889 \\
\hline Area $\left(\mathrm{m}^{2}\right)$ & 1200 & 900 & 900 \\
\hline
\end{tabular}

${ }^{1} \mathrm{SE}, \mathrm{SW}, \mathrm{NE}$, and $\mathrm{N}$ in the "Slope aspect" column in the table refer to southeast, southwest, northeast, and north, respectively.

\subsection{Tree-Ring Data}

All samples were air dried and sanded to a high polish until tree-ring boundaries and cellular structure could be easily distinguished by the naked eye, so that they could visually cross-dated using the standard methodology [25]. Ring widths were measured to a precision of $0.01 \mathrm{~mm}$ using a stage micrometer (LINTAB 6; Rinntech, Heidelberg, Germany) [26]. Cross-dating was confirmed using COFECHA software [27]. Ring width series were standardized and autoregressive log-transformed using the ARSTAN software program [28]. Age-related growth trends in raw ring-width measurement series were removed by fitting with negative exponential curves, while most low-frequency variations that could potentially be climate driven were retained. If negative exponential curves failed, a straight line of any slope gradient would be applied in its place [29]. Three standard chronologies with strong common signals and persistence were generated and then used for the following analysis (Figure 2). Furthermore, several descriptive statistics were calculated for chronologies: standard 
deviations (sd) assessed measurement variance for the whole series; mean sensitivities (ms) quantified inter-annual variation in growth between two adjacent rings; and first order autocorrelations (ac1) estimated the persistence of chronologies. Common signal strength was evaluated by percent variance explained by the first principle components (PC1) and by the mean inter-series correlations (rbar). The signal-to-noise ratios (SNR) served as an expression of the strength of the observed common signal between trees. The expressed population signals (EPS) were used to determine statistically-reliable chronology time periods using a 30-year moving window with 15 -year overlaps. The inter-annual differences (i.e., the value in the current year minus that of the previous year) in radial growth (IADR) were then calculated based on the standard ring-width indices.
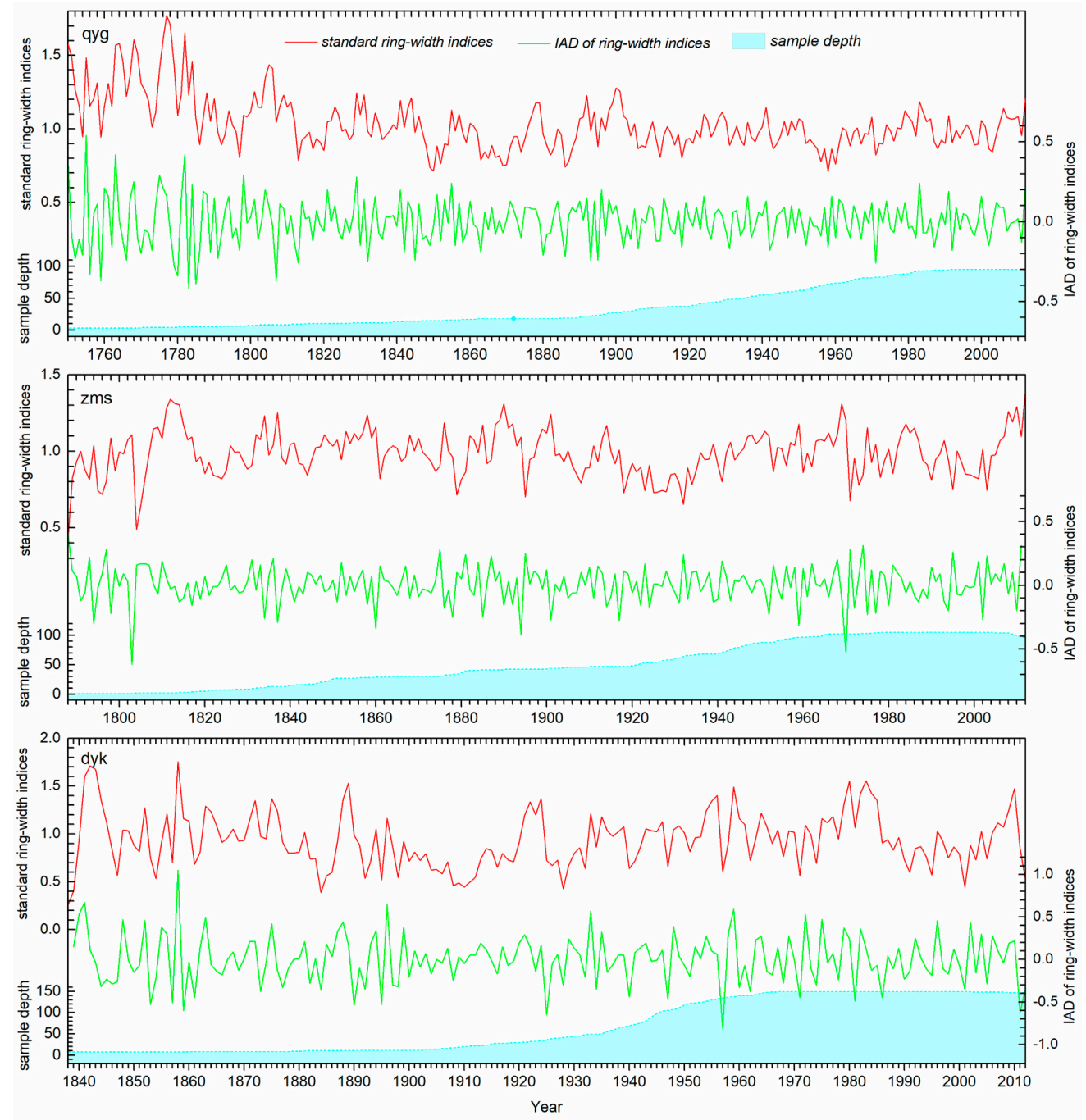

Figure 2. Standard tree-ring width chronologies and inter-annual difference (IAD) of ring-width indices for Qinghai spruce from the three sample sites.

\subsection{Meteorological Data}

The instrumental meteorological dataset used in the following analysis was taken from the Qilian meteorological station, the nearest meteorological station to the study sites. The inter-annual differences in temperature (IADT) and precipitation (IADP) were then calculated based on the instrumental data. Drought indices including the Standardized Precipitation-Evapotranspiration Index (SPEI) obtained from the Spanish National Research Council [30] and the Palmer Drought Severity Index (PDSI) obtained from the Climatic Research Unit (CRU) [31] and University Corporation for Atmospheric Research Data Center (UCAR) [32] were used to assess the drought condition of the Heihe River Basin. 
Cloud fraction data were also obtained from CRU [33] for the following analysis. NCEP/NCAR mean daily $500 \mathrm{hPa}$ geopotential height obtained from NOAA were used to calculate the regional westerly index according to the definition of Rossby and collaborators [34].

\subsection{Statistical Methods}

Climate-growth relationships were analyzed to identify the major influencing factors on tree growth using Pearson correlation analysis and response function analysis [35]. We developed a transfer function using multiple linear regression based on the climate-growth relationships [12]. Split-period calibration/verification and leave-one-out cross-validation were selected to verify the reconstruction [36]. Additionally, we used the Pearson correlation coefficient $(R)$, reduction of error $(R E)$, coefficient of efficiency $(C E)$, and sign test (ST) for statistical analysis [12]. A positive $R E$ and $C E$ value could be evidence that the regression model was valid, and the sign test could count the number of agreements and disagreements between the reconstructed and measured climatic data [37,38]. Furthermore, spatial correlation analyses between reconstruction and drought indices, as well as cloud fraction were conducted using the KNMI Climate Explorer (http:/ / climexp.knmi.nl) to detect the response of reconstructed climate factors to the regional drought and humidity conditions. Moreover, the multitaper method (MTM) for spectral analysis and the Morlet wavelet transform (Morlet 6) were used to reveal the variability of the reconstruction in the frequency domain [39-41]. Standard deviations (sd) of the reconstructed data were calculated to assessed precipitation variance for different periods and box-plots were used to analyze the distribution of the reconstructed data. Data which were one standard deviation higher or lower than the mean were identified as the extreme events. The frequencies of extreme events were calculated for different periods and we compared temporal distributions of extreme precipitation changes and extreme droughts to explore the association between them. Temporal variations of the relationship between the reconstruction and regional westerlies was accessed by moving correlation analysis. All analyses were conducted using software, including Excel (Microsoft, Seattle, DC, USA), SPSS Statistics 22 (IBM, New York, NY, USA), and Matlab R2016a (MathWorks, Natick, MA, USA).

\section{Results}

\subsection{Tree-Ring Chronology-Based Inter-Annual Differences in Radial Growth and Growth-Climate Response}

Basic statistics of the standard chronologies used in the analyses showed that the signal strengths of the three chronologies were relatively strong and the three chronologies might be suitable for climate reconstruction [12] (Table 2). The mean express population signals (EPS) values all were greater than 0.95, far higher than the acceptable threshold of $0.85[42,43]$, and all series inter-correlations (rbar) also showed high and stable values (Table 2). All of the signal to noise ratios (SNR) were higher than 20 and the highest value of the variance in the first eigenvectors (PC1) reached 54.2\%, demonstrating strong signal strength among all trees involved in the chronology (Table 2). Based on the tree-ring width indices from the three sampling sites, the inter-annual difference in radial growth (IADR) was calculated for each site. The resultant series covered the period during 1839-2012, 1749-2012, and 1789-2012, respectively (Figure 2).

Table 2. Basic statistic of standard chronologies for Qinghai spruce from three sampling sites.

\begin{tabular}{cccccccccc}
\hline Chronology & Time Span & Mean Indices & Sd $^{\mathbf{1}}$ & Ms $^{2}$ & PC1/\% $^{3}$ & Ac1 $^{\mathbf{4}}$ & Rbar $^{\mathbf{5}}$ & SNR $^{\mathbf{6}}$ & EPS $^{\mathbf{7}}$ \\
\hline dyk & $1838-2012$ & 0.94 & 0.28 & 0.24 & 51.20 & 0.36 & 0.47 & 60.03 & 0.98 \\
qyg & $1750-2012$ & 0.96 & 0.25 & 0.15 & 31.40 & 0.40 & 0.27 & 22.30 & 0.96 \\
zms & $1788-2012$ & 0.98 & 0.15 & 0.12 & 35.00 & 0.43 & 0.35 & 44.61 & 0.98 \\
\hline
\end{tabular}

${ }^{1} \mathrm{sd}$ is chronology common interval standard deviation; ${ }^{2} \mathrm{~ms}$ is mean sensitivity; ${ }^{3} \mathrm{PC} 1$ is the variance in the first eigenvalue contained in each chronology; ${ }^{4}$ ac1 is first order tree-ring series auto-correlation coefficient; ${ }^{5}$ rbar indicated all series inter-correlation; ${ }^{6}$ SNR is signal-to-noise ratio; ${ }^{7} \mathrm{EPS}$ is the express population signal. 
We tried to identify the leading limiting factor of Qinghai spruce radial growth at all three sampling sites. However, in the early and middle parts of the growing season (May-August), the response of Qinghai spruce growth to climate factors varied at different sampling stands, which might result from the differences of topography as well as tree age (Figure 3). In contrast, during the late growing season (September-October), Qinghai spruce growth were negatively correlated with precipitation at all three sampling sites, though the correlations were not significant (the lowest $p$ value is 0.51 ). A more noteworthy finding was that inter-annual differences in precipitation in September-October significantly $(p<0.05)$ limited inter-annual changes of Qinghai spruce radial growth at all three sampling sites. Direct evidence for this was that the inter-annual differences in radial growth were significantly and negatively $(p<0.05)$ correlated with inter-annual differences in precipitation during September-October (Figure 3).
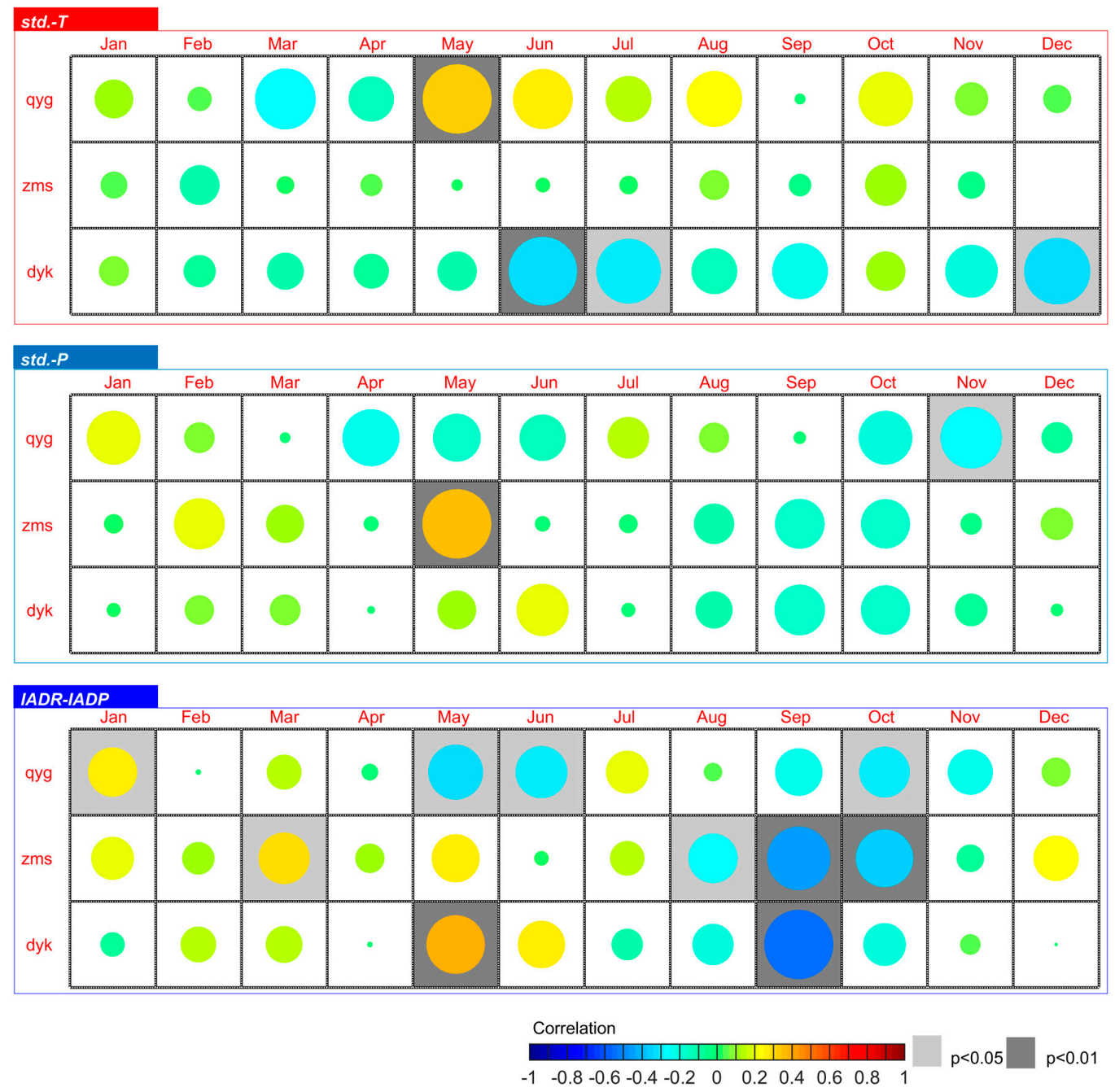

Figure 3. Climate-growth response of Qinghai spruce at all sampling sites; the upper panel shows correlations between standard wring width indices (std.) and temperature (T), the middle panel shows the correlations between standard wring width indices (std.) and precipitation ( $\mathrm{P}$ ), and the lower panel shows correlations between the inter-annual difference of standard wring width indices (IADR) and the inter-annual difference of precipitation (IADP); the larger the circle is, the stronger the correlation.

\subsection{Reconstruction of the Inter-Annual Differences in September-October Precipitation}

Based on the significant correlation between inter-annual differences in radial growth and the inter-annual differences in precipitation during September-October, we selected the inter-annual 
difference of September-October precipitation as the climate parameter for reconstruction. We developed a transfer function through multiple linear regression using the inter-annual difference of September-October precipitation as the dependent variable and the ring-width indices-based inter-annual differences in radial growth from three separated sites as the independent variables (Figure $4 \mathrm{a})$. The final calibration model explained $41.4 \%(p<0.001)$ of the total variation in the measured inter-annual differences in September-October precipitation from 1957 to 2012. The $F$ value was 12.22 and the Durbin-Watson value $(D W)$ was 2.39 , which indicated that the model was successful in describing relationships between the inter-annual differences in September-October precipitation and the inter-annual differences in radial growth. The split-period calibration/verification and leave-one-out cross-validation method, which were selected to verify the reconstruction, yielded positive REs and CEs, indicating acceptable predictive ability of the regression model (Table 3). Statistically significant sign test (ST) and Pearson's correlation coefficients $(R)$ between the measured values and the verification-period estimates also support the validity of the reconstruction (Table 3). The multiple linear model can therefore be used to reconstruct variations in inter-annual differences in precipitation during September-October since 1839.
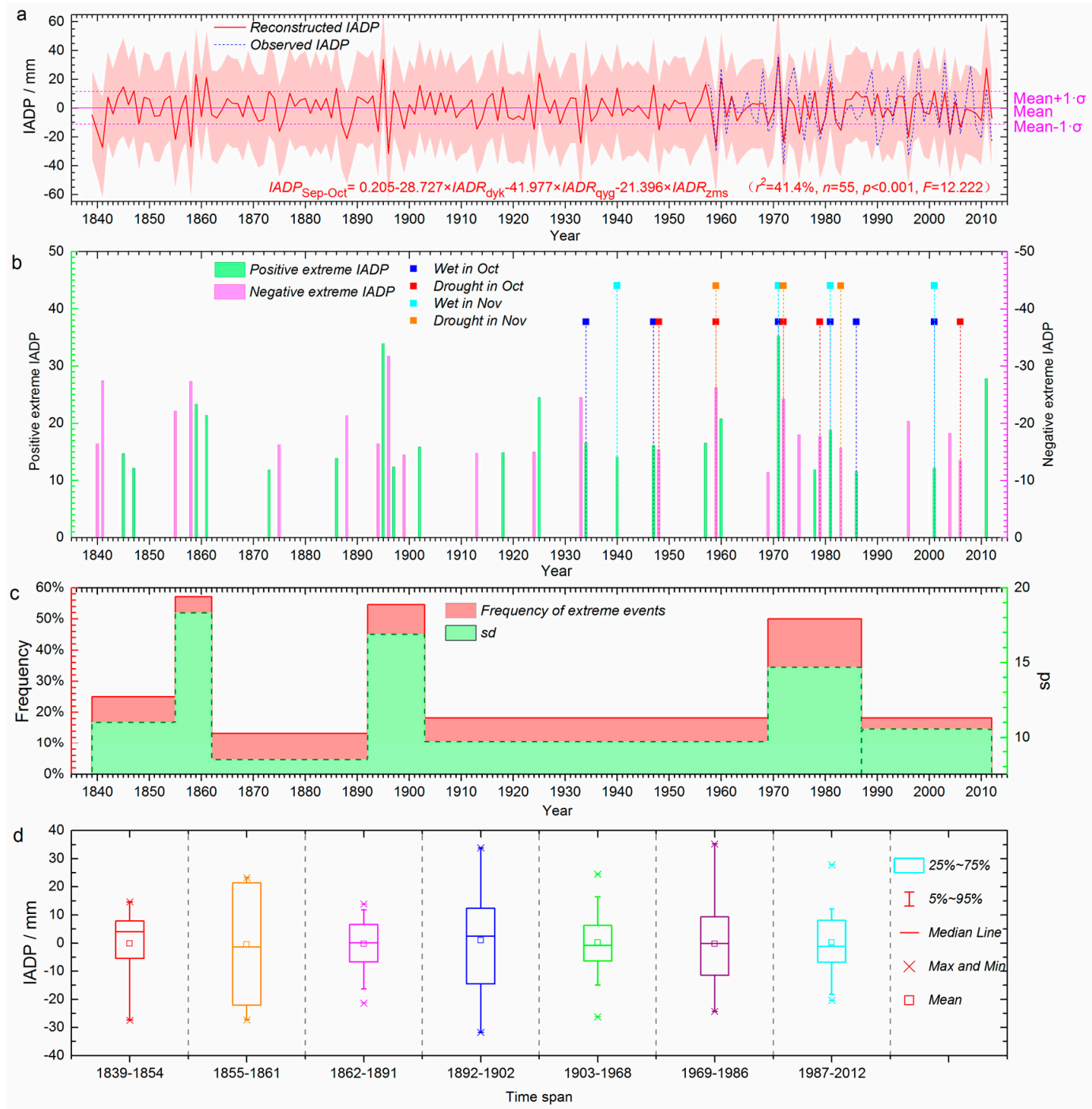

Figure 4. (a) Reconstructed inter-annual differences in precipitation in September-October; (b) comparison between extreme inter-annual changes in precipitation and extreme droughts/wetness in October and November derived from drought indices; (c,d) and split-period statistics for the reconstructed data. 
Table 3. Split-period and leave-one-out calibration and verification for the regression model.

\begin{tabular}{ccccc|ccccc}
\hline \multicolumn{4}{c|}{ Split-Period Calibration } & \multicolumn{5}{c}{ Split-Period Verification } \\
\hline Period & $\boldsymbol{R}$ & $\boldsymbol{R}^{\mathbf{2}}$ & $\boldsymbol{F}$ & $\boldsymbol{D W}$ & Period & $\boldsymbol{R}$ & $\boldsymbol{R} \boldsymbol{C}$ & $\boldsymbol{C} \boldsymbol{T}$ \\
\hline $1957-1986$ & 0.730 & 0.530 & 9.780 & 2.430 & $1987-2012$ & 0.500 & 0.245 & 0.250 & $21+/ 6-$ \\
$1987-2012$ & 0.600 & 0.360 & 4.190 & 2.520 & $1956-1986$ & 0.605 & 0.335 & 0.334 & $20+/ 10-$ \\
\hline \multicolumn{4}{c}{ Leave-one-out Calibration } & & \multicolumn{4}{c}{ Leave-one-out Verification } \\
\hline Period & $\boldsymbol{R}$ & $\boldsymbol{R}^{\mathbf{2}}$ & $\boldsymbol{F}$ & $\boldsymbol{D W}$ & Period & $\boldsymbol{R}$ & $\boldsymbol{R} \boldsymbol{C}$ & $\boldsymbol{C} \boldsymbol{S}$ & $\boldsymbol{S T}$ \\
\hline 1957-2012 & 0.640 & 0.410 & 12.220 & 2.390 & $1956-2012$ & 0.581 & 0.331 & 0.333 & $38+/ 18-$ \\
\hline
\end{tabular}

\subsection{Characteristics of Variations in the Reconstructed Inter-Annual Differences in Precipitation}

There was no obvious long-term variation trend in the reconstructed inter-annual difference series of the September-October precipitation (Figure 4a). Values of reconstructed inter-annual difference data fluctuated around zero, and the maximum of positive change appears in 1970-1971 (the reconstructed inter-annual difference value is $35.28 \mathrm{~mm}$, the observed inter-annual difference value is $37.70 \mathrm{~mm}$ ), the maximum of negative change appears in 1895-1896 (the reconstructed inter-annual difference value is $-31.76 \mathrm{~mm}$ ).

The years in which the value of the inter-annual differences in precipitation were one standard deviation higher or lower than the mean were considered as extreme events in precipitation changes (Figure $4 \mathrm{~b}$ ). The frequencies of extreme precipitation change events were relatively higher (higher than 50\%) in the three periods covered 1855-1861, 1892-1902 and 1969-1986 (Figure 4c). We also measured the dispersion of reconstructed data by calculating standard deviations (sd) and box-and-whisker plots. The statistical results showed greater dispersion during 1855-1861, 1892-1902, and 1969-1986 than neighboring periods (Figure $4 \mathrm{c}, \mathrm{d}$ ). These two results combined suggest increased variation in September-October precipitation in the three mentioned periods in our study area.

The MTM spectrum indicated the occurrence of significant quasiperiodic behavior during several periods, including approximately 2.16 years, 2.27 years, 2.62 years, and 3.41 years (Figure 5). We then applied wavelet analysis to jointly analyze the reconstructed series in the time and frequency domains for time-varying signals. Significant $(p<0.05)$ periods in the wavelet power spectrum were approximately from two to four years, which was similar to the results of the MTM spectral analysis. The quasi-periodicity from two to four years was significant for the entire time series (Figure 5). There was no significant long-periodic cycle being found in the reconstructed series, and this agreed with the previously mentioned result that there was no obvious long-term variation trend in the reconstructed inter-annual difference series of September-October precipitation.
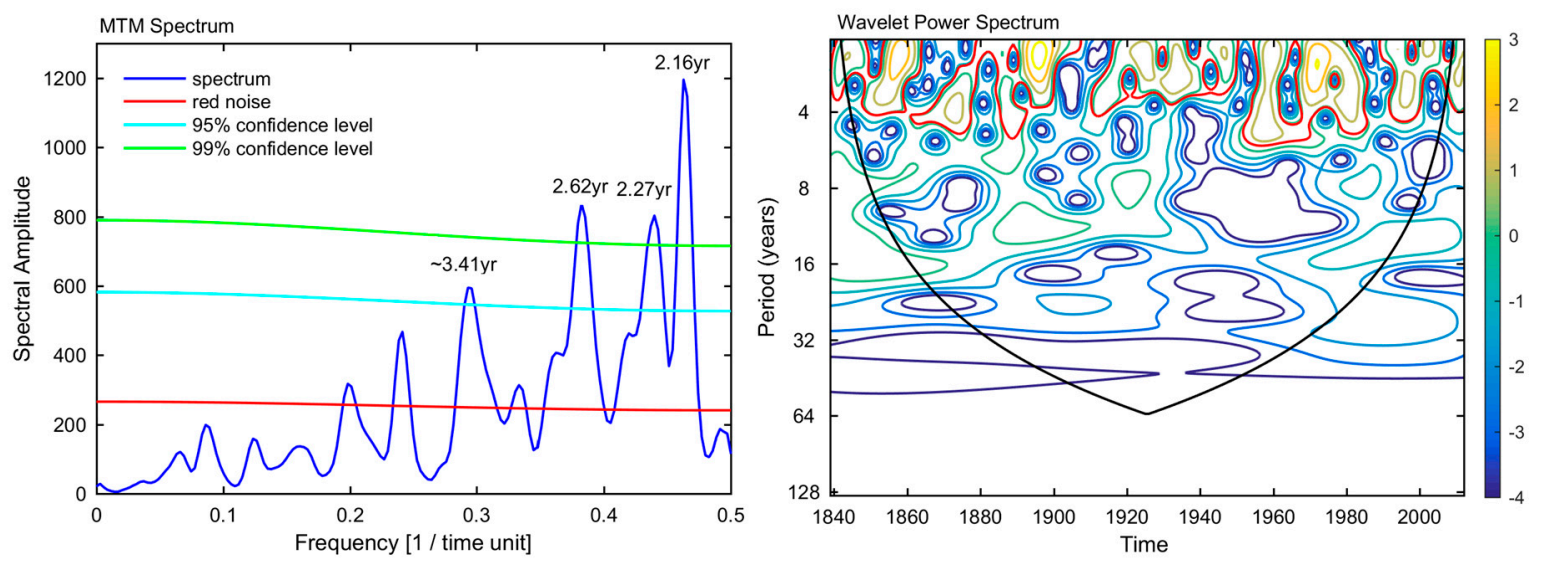

Figure 5. The multitaper method (MTM) spectrum analysis and Morlet wavelet analysis of the reconstructed inter-annual differences in September-October precipitation; the 5\% significance level against red noise is displayed as a red contour line. 


\section{Discussion}

\subsection{Impact of Precipitation on Qinghai Spruce Radial Growth in the Late Growing Season}

According to the growth-climate response analysis, we found that high precipitation in the late growing season (September-October) might have negative impacts on the radial growth of Qinghai spruce in our study area. This adverse influence of the late-growing-season precipitation also appeared in the radial growths of Schrenk spruce (Picea schrenkiana) in the Tianshan Mountains [44] and Dahurian larch (Larix gmelinii) in Northeast China [45]. A probable explanation is that excessive rainfall may weaken soil aeration by affecting moisture and oxygen content in the soil. The weakened soil aeration would inhibit physiological activities of tree roots (i.e., active absorption of water and mineral elements; nutrient absorption; and synthesis, transformation, and storage of organic compounds), which play vital roles in tree growth [45-47]. Heavy rainfalls could also lead to soil nutrient loss, thereby reducing the nutrients available to the plants [48]. Moreover, in the late growing season, excessive and heavy precipitations are not conducive to the accumulation of plant nutrients, nor the process of lignification, which is a critical procedure of tree-ring formation $[44,49]$.

\subsection{Potential Linkage between the Westerly and Increased Variabilities in September-October Precipitation}

Increased variations were found in September-October precipitation in our study area during the periods 1855-1861, 1892-1902, and 1969-1986. During 1969-1986, potential linkages were also found between the regional westerlies and this increase in precipitation variations in September-October (Figure 6). As reported by previous studies, westerlies are one of the main mechanisms of water vapor transportation in Northwest China [50]. Moreover, the research of Li et al. [51] showed a significant positive correlation $(p<0.05)$ between the water vapor transport flux in Northwest China and the regional $\left(35-50^{\circ} \mathrm{N} ; 70-110^{\circ} \mathrm{E}\right)$ westerly index. However, as shown in Figure 6, the relationship between the mentioned regional westerly index defined by Li et al. [51] and the inter-annual differences in precipitation was erratic in September-October during 1970-1986; the relationship changed from weak negative correlation to significant negative correlation, and then shifted to a significant positive correlation from negative correlation around 1985. Frequent changes in the correlation between the regional westerly index and the inter-annual differences in precipitation may be an important reason for the increase of precipitation variation in September-October during 1970-1986. However, we only have limited knowledge of past westerly changes, because the available $500 \mathrm{hPa}$ geopotential height dataset, which is essential in westerly index calculation, was limited to less than 70 years. Consequently, it is hard to determine the relationship between variations in the westerlies and precipitation during the period before 1950. It can be submitted, however, that variation of westerlies and the instability of the relationship between the westerlies and precipitation might also contribute to the increase of precipitation variation during 1855-1861 and 1892-1902 basing on the analysis mentioned above.
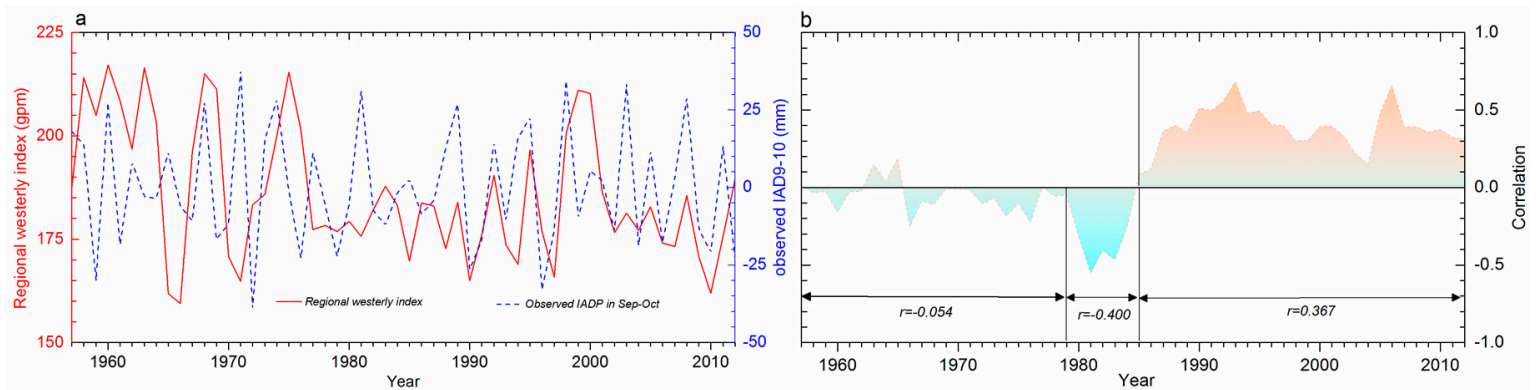

Figure 6. (a) Comparison between the September-October averaged regional westerly index and the inter-annual differences in September-October precipitation; and (b) the 11-year moving correlation between them. 
4.3. The Implications of Reconstructed Inter-Annual Differences in Precipitation for Drought Conditions in the Heihe River Basin

The tree-ring based reconstructed inter-annual differences in September-October precipitation in the present study might have implications for regional drought conditions in the Heihe river basin. Three facts mainly support this conclusion. First, a significant positive correlation $(p<0.1)$ between the observed inter-annual difference of September-October precipitation and the October SPEI_01, which is generally used to monitor and measure drought severity [30], was found in the Heihe River Basin (Figure 7a). In addition, a significant positive correlation $(p<0.1)$ between the observed inter-annual differences in precipitation and the cloud fraction, which is always considered an important moisture-related parameter [52], also existed in the region covered the Heihe River Basin during September-October (Figure 7c). The reconstructed data also significantly and positively $(p<0.1)$ correlated with the SPEI_01, as well as the cloud fraction in the same month and region (Figure 7b,d). Additionally, we extracted extreme drought and wetness events in October and November in the Heihe River Basin (38-42 ${ }^{\circ}$ N, 98-102 ${ }^{\circ}$ E) from several drought indices, including SPEI_01 [30], CRU sc_PDSI [31], and UCAR sc_PDSI [32]. In more than half of the years in which extreme (positive and negative) precipitation change events appeared in our reconstruction (13 out of 22), extreme drought or wetness synchronously emerged in the Heihe River Basin in October, November, or both months (Figure 4b). All three of these points suggest that our reconstructed data could be used as an indicator of drought conditions in the Heihe River Basin during the late growing season.
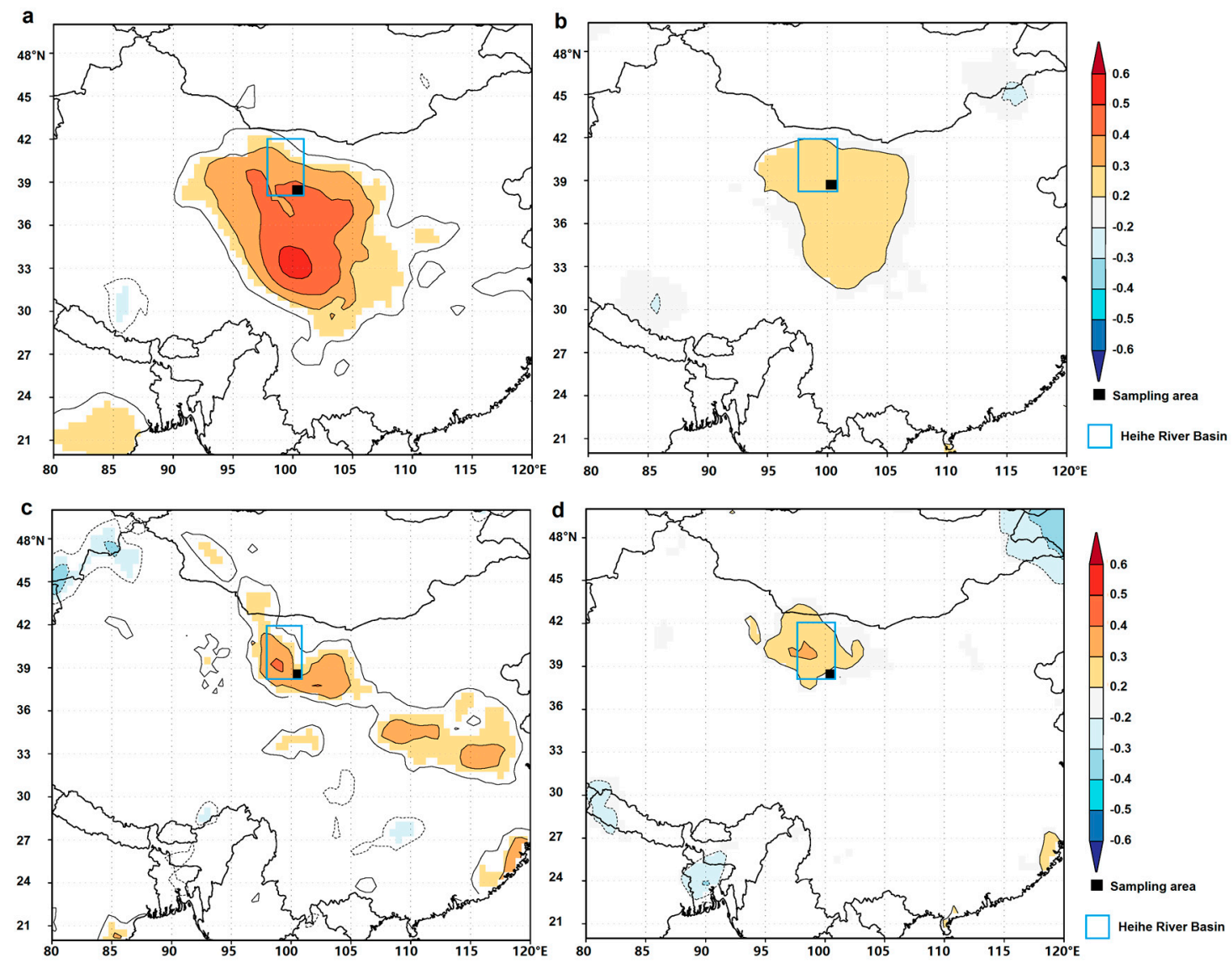

Figure 7. The spatial correlations between gridded cloud fraction data and (a) the observed-(1957-2012) and (b) reconstructed inter-annual differences in precipitation (1901-2012) in September-October; and the spatial correlations between the gridded October SPEI_01 data and (c) the observed-(1957-2012) and (d) reconstructed inter-annual differences in precipitation (1901-2012) during September-October. 


\section{Conclusions}

Inter-annual changes in Qinghai spruce radial growth in the upper reaches of the Heihe River were found to be significantly and negatively correlated with inter-annual differences in precipitation during the late growing season (September-October). Based on the growth-climate relationships, we developed a reconstruction of the inter-annual difference of September-October precipitation from 1840 in the study area. With the help of this reconstruction, we were successfully able to capture increased inter-annual variabilities in September-October precipitation during the periods 1855-1861, 1892-1902 and 1969-1986. It is more interesting that the relationship between regional westerlies and precipitation was found to be variable around 1985, when increased precipitation variation occurred, which suggests that the increased precipitation variation might be related to the variations in the westerlies. Moreover, our reconstructed data significantly correlated with the drought index (i.e., October SPEI_01) and moisture-related parameters (i.e., September-October cloud fraction) in the Heihe River Basin, which suggests that our reconstructed inter-annual differences in precipitation could be used as an indicator of drought conditions during the late growing season. These results could therefore advance our understanding of changes in precipitation and drought conditions in the Heihe River Basin.

Acknowledgments: This study was supported by the National Natural Science Foundation of China (No. 31670475), the Foundation for Innovative Research Groups of the National Natural Science Foundation of China (No. 414210610), the Foundation of Light of West China Program of Chinese Academy of Sciences, and the Youth Innovation Promotion Association, Chinese Academy of Sciences.

Author Contributions: Wang B. and Chen T. conceived and designed the experiments; Wang B., Xu G.B. and Wu G.J. performed the experiments; Wang B. analyzed the data; Wu G.J. contributed materials/analysis tools; Wang B. wrote the paper.

Conflicts of Interest: The authors declare no conflict of interest.

\section{References}

1. The Intergovernmental Panel on Climate Change (IPCC). Climate Change 2013: The Physical Science Basis. Contribution of Working Group I to the Fifth Assessment Report of the Intergovernmental Panel on Climate Change; Stocker, T.F., Qin, D., Plattner, G.K., Tignor, M., Allen, S.K., Boschung, J., Nauels, A., Xia, Y., Bex, V., Midgley, P.M., Eds.; Cambridge University Press: Cambridge, UK; New York, NY, USA, 2013; pp. 1-1535.

2. Arnell, N.W. Climate change and global water resources. Glob. Environ. Chang. 1999, 9, S31-S49. [CrossRef]

3. Vorosmarty, C.J.; McIntyre, P.B.; Gessner, M.O.; Dudgeon, D.; Prusevich, A.; Green, P.; Glidden, S.; Bunn, S.E.; Sullivan, C.A.; Liermann, C.R.; et al. Global threats to human water security and river biodiversity. Nature 2010, 467, 555-561. [CrossRef] [PubMed]

4. Vörösmarty, C.J.; Green, P.; Salisbury, J.; Lammers, R.B. Global water resources: Vulnerability from climate change and population growth. Science 2000, 289, 284-288. [CrossRef] [PubMed]

5. Allen, C.D.; Macalady, A.K.; Chenchouni, H.; Bachelet, D.; McDowell, N.; Vennetier, M.; Kitzberger, T.; Rigling, A.; Breshears, D.D.; Hogg, E.H.; et al. A global overview of drought and heat-induced tree mortality reveals emerging climate change risks for forests. For. Ecol. Manag. 2010, 259, 660-684. [CrossRef]

6. Yao, T.; Duan, K.; Xu, B.; Wang, N.; Guo, X.; Yang, X. Ice core precipitation record in central Tibetan plateau since AD 1600. Clim. Past Discuss. 2008, 4, 233-248. [CrossRef]

7. Burn, M.J.; Holmes, J.; Kennedy, L.M.; Bain, A.; Marshall, J.D.; Perdikaris, S. A sediment-based reconstruction of Caribbean effective precipitation during the 'Little Ice Age' from Freshwater Pond, Barbuda. Holocene 2016, 26, 1237-1247. [CrossRef]

8. Zhou, W.; Xian, F.; Du, Y.; Kong, X.; Wu, Z. The last 130 ka precipitation reconstruction from Chinese loess10Be. J. Geophys. Res. Solid Earth 2014, 119, 191-197. [CrossRef]

9. Schäbitz, F.; Wille, M.; Francois, J.-P.; Haberzettl, T.; Quintana, F.; Mayr, C.; Lücke, A.; Ohlendorf, C.; Mancini, V.; Paez, M.M.; et al. Reconstruction of palaeoprecipitation based on pollen transfer functions-The record of the last 16 ka from Laguna Potrok Aike, southern Patagonia. Quat. Sci. Rev. 2013, 71, 175-190. [CrossRef] 
10. Sun, J.H.; Li, F.R.; Zhao, W.W.; Tang, Y. A review of the studies on modern process for climatic proxies in north-western China. Front. Earth Sci. 2011, 5, 262-270. [CrossRef]

11. PAGES. Continental-scale temperature variability during the past two millennia. Nat. Geosci. 2013, 6, 339-346.

12. Cook, E.R.; Kairiukstis, L.A. Methods of Dendrochronology: Applications in the Environmental Sciences, 1st ed.; Springer: Berlin, Germany, 1990; pp. 1-394.

13. Yang, B.; Qin, C.; Wang, J.; He, M.; Melvin, T.M.; Osborn, T.J.; Briffa, K.R. A 3500-year tree-ring record of annual precipitation on the northeastern Tibetan Plateau. Proc. Natl. Acad. Sci. USA 2014, 111, 2903-2908. [CrossRef] [PubMed]

14. Zhang, Y.; Tian, Q.H.; Gou, X.H.; Chen, F.H.; Leavitt, S.W.; Wang, Y.S. Annual precipitation reconstruction since AD 775 based on tree rings from the Qilian Mountains, northwestern China. Int. J. Climatol. 2011, 31, 371-381. [CrossRef]

15. Chen, F.; Yuan, Y.J.; Wei, W.S.; Zhang, R.B.; Yu, S.L.; Shang, H.M.; Zhang, T.W.; Qin, L.; Wang, H.Q.; Chen, F.H. Tree-ring-based annual precipitation reconstruction for the Hexi Corridor, NW China: Consequences for climate history on and beyond the mid-latitude Asian continent. Boreas 2013, 42, 1008-1021. [CrossRef]

16. Yang, B.; Qin, C.; Brauning, A.; Burchardt, I.; Liu, J.J. Rainfall history for the Hexi Corridor in the arid northwest China during the past 620 years derived from tree rings. Int. J. Climatol. 2011, 31, 1166-1176. [CrossRef]

17. Gallinat, A.S.; Primack, R.B.; Wagner, D.L. Autumn, the neglected season in climate change research. Trends Ecol. Evol. 2015, 30, 169-176. [CrossRef] [PubMed]

18. Qin, D.H. China National Assessment Report on Risk maNagement and Adaptation of Climate Extremes and Disasters; Qin, D.H., Zhang, J.Y., Shan, C.C., Song, L.C., Eds.; Science Press: Beijing, China, 2015; pp. 1-124.

19. Zhang, W.J.; Jin, F.F.; Turner, A. Increasing autumn drought over southern China associated with ENSO regime shift. Geophys. Res. Lett. 2014, 41, 4020-4026. [CrossRef]

20. Liu, Y.; Lei, Y.; Sun, B.; Song, H.; Li, Q. Annual precipitation variability inferred from tree-ring width chronologies in the Changling-Shoulu region, China, during AD 1853-2007. Dendrochronologia 2013, 31, 290-296. [CrossRef]

21. Liu, Y.; Sun, B.; Song, H.; Lei, Y.; Wang, C. Tree-ring-based precipitation reconstruction for Mt. Xinglong, China, since AD 1679. Quat. Int. 2013, 283, 46-54. [CrossRef]

22. Tian, Q.; Gou, X.; Zhang, Y.; Peng, J.; Wang, J.; Chen, T. Tree-ring based drought reconstruction (A.D. 1855-2001) for the Qilian Mountains, northwestern China. Tree-Ring Res. 2007, 63, 27-36. [CrossRef]

23. Deng, Y.; Gou, X.H.; Gao, L.L.; Zhao, Z.Q.; Cao, Z.Y.; Yang, M.X. Aridity changes in the eastern Qilian Mountains since AD 1856 reconstructed from tree-rings. Quat. Int. 2013, 283, 78-84. [CrossRef]

24. Gou, X.H.; Deng, Y.; Gao, L.L.; Chen, F.H.; Cook, E.; Yang, M.X.; Zhang, F. Millennium tree-ring reconstruction of drought variability in the eastern Qilian Mountains, northwest China. Clim. Dyn. 2014, 45, 1761-1770. [CrossRef]

25. Stokes, M.A.; Smiley, T.L. An Introduction to Tree-Ring Dating; University of Arizona Press: Tucson, AZ, USA, 1996; pp. 1-73.

26. Rinn, F. TSAP-Win ${ }^{\mathrm{TM}}$ : Time Series Analysis and Presentation for Dendrochronology and Related Applications. Version 4.64 for Microsoft Windows User Reference; Rinntech: Heidelberg, Germany, 2011; p. 110.

27. Holmes, R.L. Computer-assisted quality control in tree-ring dating and measurement. Tree-Ring Bull. 1983, 43, 69-78.

28. Cook, E.R.; Holmes, R.L. Users Manual for Program ARSTAN; Laboratory of Tree-Ring Research, University of Arizona: Tucson, AZ, USA, 1986; pp. 1-81.

29. Cook, E.R. A Time Series Analysis Approach to Tree Ring Standardization (Dendrochronology, Forestry, Dendroclimatology, Autoregressive Process). Ph.D. Thesis, University of Arizona, Tucson, AZ, USA, 1985.

30. Vicente-Serrano, S.M.; Beguería, S.; López-Moreno, J.I. A Multiscalar Drought Index Sensitive to Global Warming: The Standardized Precipitation Evapotranspiration Index. J. Clim. 2010, 23, 1696-1718. [CrossRef]

31. Van der Schrier, G.; Barichivich, J.; Briffa, K.R.; Jones, P.D. A scPDSI-based global data set of dry and wet spells for 1901-2009. J. Geophys. Res. Atmos. 2013, 118, 4025-4048. [CrossRef]

32. Dai, A.; Trenberth, K.E.; Qian, T. A global dataset of Palmer Drought Severity Index for 1870-2002: Relationship with soil moisture and effects of surface warming. J. Hydrometeorol. 2004, 5, 1117-1130. [CrossRef] 
33. Harris, I.; Jones, P.D.; Osborn, T.J.; Lister, D.H. Updated high-resolution grids of monthly climatic observations-the CRU TS3.10 Dataset. Int. J. Climatol. 2014, 34, 623-642. [CrossRef]

34. Rossby, C.G. Collaborators Relation between Variations in the Intensity of the Zonal Circulation of the Atmosphere and the Displacements of the Semi-permanent Centers of Action. J. Mar. Res. 1939, 2, 38-55. [CrossRef]

35. Samuels, P. Gilchrist, M. Pearson Correlation; Birmingham City University: Birmingham, UK, 2014; pp. 1-4.

36. Michaelsen, J. Cross-validation in statistical climate forecast models. J. Clim. Appl. Meteorol. 1987, 26, 1589-1600. [CrossRef]

37. Fritts, H.C. Tree Rings and Climate; Elsevier: London, UK, 1976; pp. 1-567.

38. Schweingruber, F.H. Tree Rings: Basics and Applications of Dendrochronology, 1st ed.; Springer: Dordrecht, The Netherlands; Boston, MA, USA; London, UK, 1988; pp. 1-276.

39. Grinsted, A.; Moore, J.C.; Jevrejeva, S. Application of the cross wavelet transform and wavelet coherence to geophysical time series. Nonlinear Process. Geophys. 2004, 11, 561-566. [CrossRef]

40. Michael, S.; Mudelsee, M. REDFIT: Estimating red-noise spectra directly from unevenly spaced paleoclimatic time series. Comput. Geosci. 2002, 28, 421-426.

41. Torrence, C.; Compo, G.P. A practical guide to wavelet analysis. Bull. Am. Meteorol. Soc. 1998, 79, 61-78. [CrossRef]

42. Wigley, T.M.; Briffa, K.R.; Jones, P.D. On the average value of correlated time series, with applications in dendroclimatology and hydrometeorology. J. Clim. Appl. Meteorol. 1984, 23, 201-213. [CrossRef]

43. Buras, A. A comment on the expressed population signal. Dendrochronologia 2017, 44, 130-132. [CrossRef]

44. Sang, W.; Wang, Y.; Su, H.; Lu, Z. Response of tree-ring width to rainfall gradient along the Tianshan Mountains of northwestern China. Chin. Sci. Bull. 2007, 52, 2954-2962. [CrossRef]

45. Bai, X. Study on the Lag Responses of Dahurian Larch Radial Growth to Climate Change. Master's Thesis, Shenyang Agriculture University, Shenyang, China, 2016.

46. Abramoff, R.Z.; Finzi, A.C. Are above- and below-ground phenology in sync? New Phytol. 2015, 205, 1054-1061. [CrossRef] [PubMed]

47. Goodwin, C.; Lumis, G. Embedded wire in tree roots: Implications for tree growth and root function. J. Arboric. 1992, 18, 115-123.

48. Alkaisi, M.; Helmers, M. Heavy Rain, Soil Erosion and Nutrient Losses. Integrated Crop Management News, 2008, p. 891.

49. Patel, V.R.; Pramod, S.; Rao, K.S. Cambial activity, annual rhythm of xylem production in relation to phenology and climatic factors and lignification pattern during xylogenesis in drum-stick tree (Moringa oleifera). Flora-Morphol. Distrib. Funct. Ecol. Plants 2014, 209, 556-566. [CrossRef]

50. Guo, X.; Feng, Q.; Wei, Y.; Li, Z.; Liu, W. An overview of precipitation isotopes over the Extensive Hexi Region in NW China. Arab. J. Geosci. 2014, 8, 4365-4378. [CrossRef]

51. Li, W.L.; Wang, K.L.; Fu, S.M.; Jiang, H. The interrelationship between regional westerly index and the water vapor budget in Northwest China. J. Glaciol. Geocryol. 2008, 30, 28-34.

52. Liu, X.; Xu, G.; Grießinger, J.; An, W.; Wang, W.; Zeng, X.; Wu, G.; Qin, D. A shift in cloud cover over the southeastern Tibetan Plateau since 1600: Evidence from regional tree-ring $\delta^{18} \mathrm{O}$ and its linkages to tropical oceans. Quat. Sci. Rev. 2014, 88, 55-68. [CrossRef]

(c) 2017 by the authors. Licensee MDPI, Basel, Switzerland. This article is an open access article distributed under the terms and conditions of the Creative Commons Attribution (CC BY) license (http://creativecommons.org/licenses/by/4.0/). 